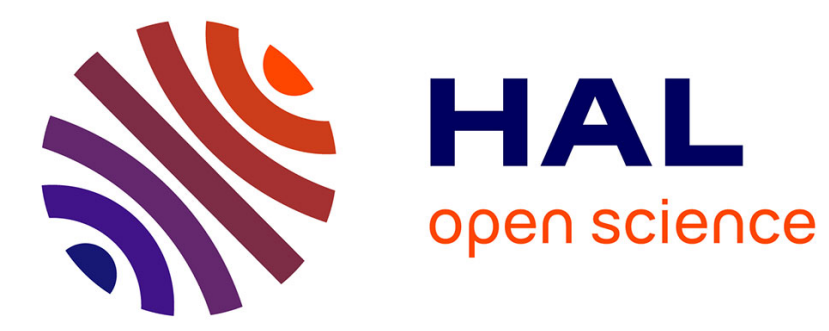

\title{
Thermal insulation with 2D materials: liquid phase exfoliated vermiculite functional nanosheets
}

Iwona Janica, Stefano del Buffa, Agnieszka Mikolajczak, Matilde Eredia, Dawid Pakulski, Artur Ciesielski, Paolo Samorì

\section{- To cite this version:}

Iwona Janica, Stefano del Buffa, Agnieszka Mikolajczak, Matilde Eredia, Dawid Pakulski, et al.. Thermal insulation with 2D materials: liquid phase exfoliated vermiculite functional nanosheets. Nanoscale, 2018, 10 (48), pp.23182-23190. 10.1039/C8NR08364A . hal-01985436

\section{HAL Id: hal-01985436 https://hal.science/hal-01985436}

Submitted on 25 Jan 2019

HAL is a multi-disciplinary open access archive for the deposit and dissemination of scientific research documents, whether they are published or not. The documents may come from teaching and research institutions in France or abroad, or from public or private research centers.
L'archive ouverte pluridisciplinaire HAL, est destinée au dépôt et à la diffusion de documents scientifiques de niveau recherche, publiés ou non, émanant des établissements d'enseignement et de recherche français ou étrangers, des laboratoires publics ou privés. 


\section{Journal Name}

\section{ARTICLE}

\section{Thermal insulation with 2D materials: liquid phase exfoliated vermiculite functional nanosheets}

Received 00th January 20xx, Accepted 00th January 20xx

DOI: $10.1039 / x 0 x \times 00000 x$

www.rsc.org/

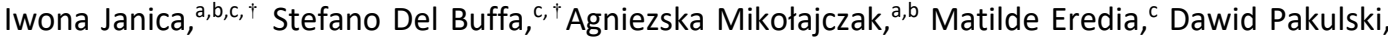 \\ a,b,c Artur Ciesielski, ${ }^{* b, c}$ Paolo Samorì, ${ }^{* c}$
}

\section{Introduction}

Clays, belonging to the phyllosilicate minerals group, have been known to mankind for centuries and over the years they became more and more popular because of their unique structure, surface chemistry, adsorption characteristics, thermal/mechanical properties, natural abundance and environment-friendly nature. ${ }^{1}$ The presence of stacked crystalline layers within their structure, allows clay minerals to be processed into nano-sized building blocks, i.e., 2D exfoliated nanosheets. ${ }^{2-4}$ Among various clays, vermiculite represents a valuable example of a natural, highly-charged aluminosilicate with tremendous industrial relevance. Vermiculite exhibits a layered 2:1 phyllosilicate structure composed of octahedral sheets containing magnesium ions, sandwiched between two

a. Faculty of Chemistry, Adam Mickiewicz University in Poznań, Umultowska 89b, 61-614 Poznań, Poland.

b. Centre for Advanced Technologies, Adam Mickiewicz University, Umultowska 89c, 61-614 Poznań, Poland.

c. Université de Strasbourg, CNRS, ISIS, 8 allée Gaspard Monge, 67000 Strasbourg, France.

† These authors contributed equally.

Electronic Supplementary Information (ESI) available. See DOI: 10.1039/x0xx00000x tetrahedral silicate layers (Figure 1), in which silicon is partially replaced by aluminum. ${ }^{5}$ The interlayer area between the parallel 2:1 layers contains water molecules and weakly bounded thus exchangeable cations, such as $\mathrm{Na}^{+}, \mathrm{K}^{+}, \mathrm{Mg}^{2+}$ and $\mathrm{Ca}^{2+}$, that compensate the positive charge deficiency arising from $\mathrm{Al}^{3+}$ substitution in the tetrahedral layers. ${ }^{6,7}$

Due to its unique thermal properties, vermiculite can be used as the mineral component of phase change materials ${ }^{8}$ and in hightemperature, refractory insulation. Vermiculite has been widely reported to enhance the intumescent flame retardancy of polymeric materials, such as lignocellulosic materials, ${ }^{9}$ polypropylene ${ }^{10}$ or polyorganosiloxanes. ${ }^{11}$ Recently, vermiculite has been also exploited to enhance the thermal properties of PEG-based films ${ }^{12}$, LbL self-assembled chitosan-based coatings $^{13}$ and flexible polyurethane foams. ${ }^{14}$ When such nanocomposites are directly exposed to a flame, a charred clay layer is formed, acting as an insulating shield and a barrier to volatiles released from the polymer matrix, thus improving thermal properties and fire resistance of the composite material. In addition to that, as long as phonon-mediated heat transport is concerned, two-dimensional materials (2DMs) can display ultralow heat conduction properties thanks to the additional thermal resistance provided by phonon scattering across ordered interfaces, thus overcoming the typical limit of 

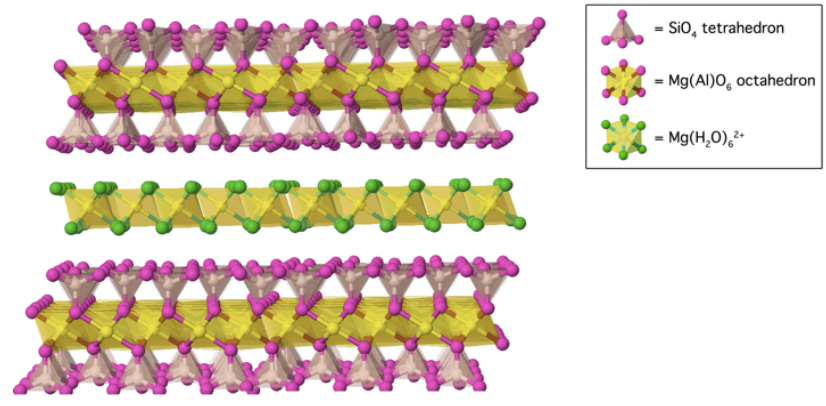

Figure 1. Schemat c representat on of vermicu te crysta ne structure showing the 2:1 sequence of tetrahedral-octahedral-terrahedra a um nos care avers, and octahedrally coordinated $\mathrm{Mg}^{2+}$ ons in the inter aver space. For $\mathrm{c}$ ar $\mathrm{tv}$, water moecues have not been incuded in the pcrure. Image adapted from https://virtual-museum.so s.w scedu d so av verm cu ce

homogenous amorphous solids. For instance, molecular beam deposited $\mathrm{WSe}_{2}$ films have been shown to exhibit the lowest thermal conductivity for a fully dense solid $\left(\lambda=0.06 \mathrm{Wm}^{-1} \mathrm{~K}^{-1}\right.$ at room temperature), thanks to the interplay of low interfacial bond stiffness and to the random stacking of well crystallized $\mathrm{WSe}_{2}$ sheets. ${ }^{15}$ Further engineering of the surface of $2 \mathrm{DMs}$ through covalent and non-covalent modifications can effectively result in a modulation of the interfacial thermal conductance (i.e., the finite drop in temperature for a given heat flux across an interface) and ultimately in a reduction of the thermal conductivity of the material. This was indeed demonstrated on Au-SAMs with varying interfacial chemistry and density of covalent bonds, ${ }^{16}$ as well as on alkylammoniumintercalated clay nanolaminates. ${ }^{17}$ By properly combining 2DMs with highly porous polymeric matrices, even lower thermal conductivity values can be reached. Wicklein et. al., ${ }^{18}$ for instance, recently reported on a light-weight anisotropic foam made by nanocellulose and graphene oxide, showing fireretardant properties and a radial thermal conductivity as low as $0.015 \mathrm{Wm}^{-1} \mathrm{~K}^{-1}$.

The top-down production of low-dimensional materials with defined size and physico-chemical properties represents a key research topic in material science and nanotechnology. In particular, during the last decade, since the first successful exfoliation of graphene, ${ }^{19}$ 2DMs attract unprecedented interest ${ }^{20,} 21$ and a variety of layered compounds (e.g., metal chalcogenides, ${ }^{22,}{ }^{23}$ oxides, $^{24}$ clays $^{25}$ ) are being exfoliated from bulk crystals or powders. The resulting one- or few-layer thick nanosheets exhibit promising physico-chemical properties particularly appealing for applications in sensing, ${ }^{26}$ mechanical reinforcement and flexible devices, ${ }^{27}$ (photo-)catalysis, ${ }^{28,}{ }^{29}$ and (opto)electronics. ${ }^{30}, 31$ Nevertheless, the translation of the outstanding properties of $2 \mathrm{DMs}$, which are observed on labscale experiments, into real-world applications on an industrial scale suffers from major drawbacks associated to 2DMs' production, and in particular, to the lack of up-scalable production processes.

Due to the presence of relatively weak non-covalent inter-layer interactions vermiculite can be expanded and ultimately exfoliated into one- to few-layer thick sheets. ${ }^{32,} 33$ Noteworthy, the degree of exfoliation depends on the composition of the starting material, particle size, nature of interlayer cations, water content, as well as the type of solvent and temperature employed during the exfoliation. The most well-known method of expanding vermiculite crystals relies on rapid heating of the mineral at high temperature $\left(\approx 1000^{\circ} \mathrm{C}\right)$ during short period of time (few minutes). As a result, the expanded material exhibits increased porosity, with a typical accordion-like morphology and a different crystalline structure. ${ }^{34,35}$ Wet chemical methods are employed to further improve the exfoliation yields, using hydrogen peroxide ${ }^{36,37}$ or mineral acids, such as $\mathrm{HNO}_{3}, \mathrm{H}_{2} \mathrm{SO}_{4}$ or $\mathrm{HCl}^{38}, 39$ Nevertheless, in most cases, the experimental conditions are relatively harsh (i.e., high concentration of acid, prolonged contact times), leading to the formation of amorphous silica, while other structural components of vermiculite are leached out. ${ }^{40,41}$ Acid treatment of vermiculite leads to the substitution of interlayer cations with protons and produces Brønsted acidic $\mathrm{Si}-\mathrm{OH}$ at the layer edges, ${ }^{42}$ which in turns increase the number of reactive sites towards ion binding and surface chemical modifications. ${ }^{43}$ Moreover, ultrasounds and microwaves can be successfully employed during exfoliation of vermiculite in aqueous solutions. $33,44-46$ Ultrasound-assisted exfoliation has been found to be more robust in terms of energy saving and lower exfoliation temperature comparing to thermal-based processes. Moreover, ultrasounds cause a substantial decrease in particle size reaching nanometer dimensions along the [0OI] lattice direction. ${ }^{33}, 44,45,47,48$ Importantly, mixed layer (micavermiculite) minerals always produce better exfoliation than pure vermiculite, giving rise to materials with higher specific surface area and expansive capacity, ${ }^{34}$ whereas pure vermiculite does not undergo exfoliation or does so only to a smaller extent. ${ }^{35}$ Ultrasound-assisted exfoliation of vermiculite is generally conducted in water or hydrogen peroxide solutions during long period of time (up to $150 \mathrm{~h})^{47}$ using low ultrasonic frequencies $(20 \mathrm{kHz})$ and high output power $(350-750 \mathrm{~W}) .^{49}$ To the best to our knowledge, the production of ultrathin vermiculite flakes using ultrasonication in acidic solutions has not been investigated to date.

Vermiculite, as well as other analogous minerals (e.g., montmorillonite, kaolinite), are used in combination with organic molecules and polymers to obtain functionalized clay materials, ordered self-assembled nanostructures ${ }^{50}$ and polymer-based nanocomposites, ${ }^{48,51,52}$ displaying interesting and improved physical and chemical properties. In particular, materials with enhanced stiffness, toughness, strength and thermal stability can be obtained, 53,54 exhibiting increased affinity towards organic pollutants ${ }^{43}$ and metal ions, $48,55,56$ enhanced gas barrier and thermal insulating properties. ${ }^{57}$ Regardless of the application and the functionalization strategy, the quality of the starting clay (in terms of size distribution, aspect ratio, number of layers, etc.) is a key parameter, ultimately affecting both properties and potential applications of the final material. To this end, various efforts have been made in the development of different production methods particularly employing cheap, low-purity materials containing different layered clays. ${ }^{58}$

To achieve a full understanding of the exfoliation of vermiculite in aqueous environment, here we performed ultrasound- 
assisted exfoliation of vermiculite in acidic solutions. Furthermore, following the approach by Paton et al. for the production of graphene, ${ }^{59}$ we employed shear mixing approach towards the production of vermiculite nanosheets. This comparative study was carried out to unravel the effect of ultrasounds and shear forces on the exfoliation of cheap, multiphasic vermiculite crystals into mono- and few-layer thick nanosheets. We compared the quality of the materials obtained with the two approaches in terms of particle size distribution, thickness/lateral size of exfoliated flakes and specific surface area. Finally, as a proof-of-concept, we performed thermal conductivity measurements on the exfoliated vermiculite showing how the newly-formed structure beneficially affect the thermal insulating properties of the material.

\section{Results and discussion}

Both, ultrasounds and shear-mixing approaches rely on weakening and ultimately rupture of the vermiculite layered structure by applying mechanical stress. However, the mechanism of the two exfoliation approaches differs significantly (Figure 2). Ultrasounds can produce a multitude of mechanical, thermal and physicochemical effects, such as reduction in flake size, modification of textural properties, crystallinity and dispersion, ${ }^{49}$ as a result of the cavitation phenomenon via the formation, growth and collapse of gaseous microbubbles in the liquid medium that can generate locally high pressures (up to 1000 bar) and temperatures (up to 5000 K). ${ }^{60}$ The distribution of cavities depends on the geometry of the ultrasonic probe, the ultrasound density and frequency and the solvent. Ultrasonication can not only promote the liquid-phase exfoliation of clays and related minerals into 2DMs, but under certain conditions can also lead to severe structural rearrangements leading, for instance, to the curling of the clay layers and the formation of tubular nanostructures, as reported by Li et. al. on alkylammonium-intercalated kaolinite. ${ }^{61}$

On the other hand, during shear-mixing a high-speed rotor causes the mixing of the dispersion in both low and high viscosity solvents. When the difference in velocity of the rotor tip and that of the surrounding fluid is higher than the velocity at the center of the rotor, shear forces are created leading to exfoliation of the dispersed material. The type of flow inside the chamber and the degree of exfoliation depend on geometrical parameters (e.g., diameter of the rotor and rotational speed), time, viscosity of the continuous phase, concentration of the dispersed phase and temperature. ${ }^{59}, 62$ Considering our experimental set-up, turbulent flow is not fully developed (Reynold number $<10^{4}$ ) and exfoliation mainly occurs in highshear laminar flow conditions. ${ }^{59}$

Grounded vermiculite was found not to generate a stable dispersion in acid solution (not even after stirring, see Figure 2a): larger particles sediment quickly, while the smaller ones float on the surface because of the presence of trapped air. After a pre-treatment in the ultrasonic bath, the solution turns brownish and becomes slightly turbid, indicating partial dispersion of the clay. Such vermiculite dispersion was used as the starting material for subsequent ultrasound-assisted

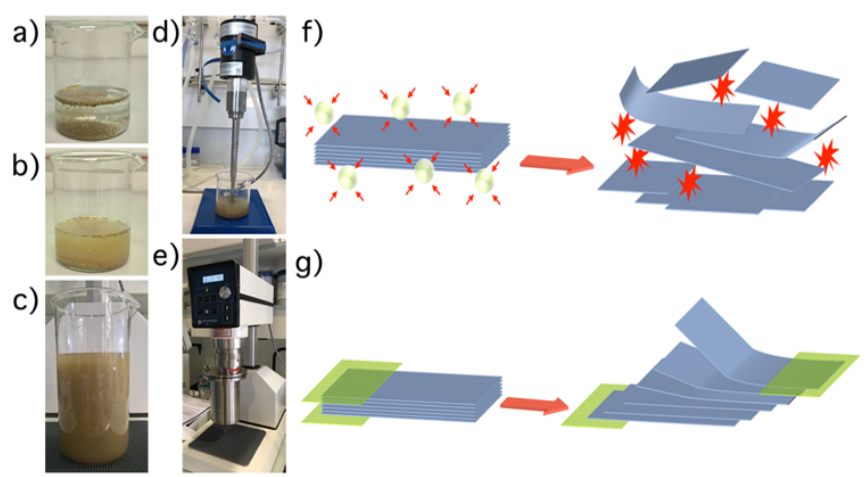

Figure 2. Production of exfoliated vermiculite by ultrasounds and shear forces: a) beaker with acidic solution after addition of vermiculite; $b$ ) vermiculite dispersion obtained after ultrasound-assisted exfoliation ( $\mathrm{pH}=3.5,3 \mathrm{~h}) ; \mathrm{c}$ ) vermiculite dispersion obtained after exfoliation by shear mixing ( $\mathrm{pH}=3.5,3000 \mathrm{rpm}, 20 \mathrm{~min})$; d) Sonopuls 3100 ultrasonic homogenizer equipped with titanium probe; e) L5M-A shear mixer; schematic representation of the exfoliation mechanism of vermiculite by $\mathrm{f}$ ) ultrasounds and $\mathrm{g}$ ) shear forces.

exfoliation processes. The visual appearance of the dispersion after the exfoliation differs significantly (Figure $2 \mathrm{~b}$ and $\mathrm{c}$ ). The amount of sediment was strongly reduced (i.e., as a consequence of the decreased particle size the colloidal stability is increased). Moreover, the brownish color was much more intense, and the suspension was more turbid, indicating a larger amount of dispersed material. A haze-looking particulate was also visible in backlight as to indicate the presence of aggregates with an ordered structure. Optical birefringence of exfoliated vermiculite dispersions is indeed documented in the literature and it is ascribed to a nematic liquid crystalline-like ordering of 2D nanosheets. ${ }^{63}$ Despite the presence of large, likely nonexfoliated, particles that sediment quickly the colloidal stability of aqueous dispersions of exfoliated vermiculite is satisfactory (ESI Fig. S1), allowing for further processing of vermiculite nanosheets in the dispersed phase (e.g., centrifugation, functionalization, etc.) or for their successful deposition onto solid surfaces (e.g., by means of spray coating, solvent casting, etc.).

In case of exfoliation in acidic solutions ( $\mathrm{pH}=3-5)$, an increase of the $\mathrm{pH}$ was always observed at the end of the process, which can be related to the exchange of interlayer cations from the vermiculite structure with hydrogen ions from acid solutions during exfoliation to individual flakes (ESI Figure S2 and S3). The largest $\mathrm{pH}$ difference before and after ultrasound-assisted exfoliation was observed at initial $\mathrm{pH}=3.5$ after $3 \mathrm{~h}$, where the final $\mathrm{pH}$ value increased to 6.8 .

Significant morphological differences can be observed in vermiculite samples before and after ultrasound-assisted exfoliation (verm-US). The SEM image (Figure 3, see experimental section for details about sample preparation) of raw vermiculite shows the presence of thick, $\mathrm{mm}$-sized particles with a multi-layered structure, whereas after exfoliation smaller flakes of different thickness and irregular shape are visible. Further insights into the degree of exfoliation, i.e. number of layers and lateral size of vermiculite flakes, as well as their changes upon variation of experimental conditions (i.e., $\mathrm{pH}$ and time), can be inferred from AFM topography images taken on 


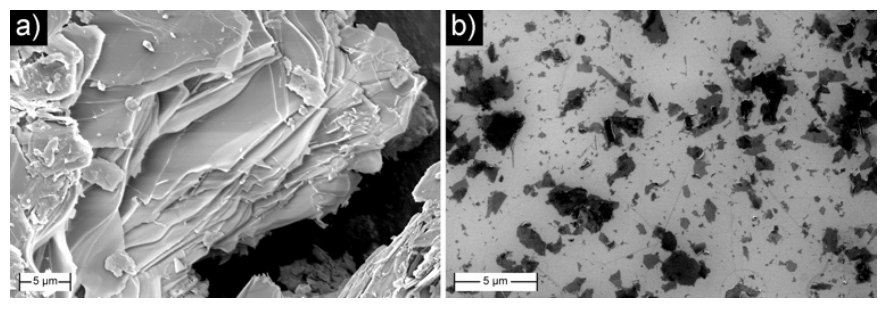

Figure 3. SEM images of a) raw vermiculite and $b$ ) vermiculite exfoliated with ultrasounds (verm-US, $\mathrm{pH}=3.5,3 \mathrm{~h}$ ). Scale bar $=5 \mu \mathrm{m}$.

vermiculite dispersions deposited on $\mathrm{Si} / \mathrm{SiO}_{2}$ substrates. In all cases, the samples are composed of polydisperse flakes with lateral size ranging from tenths of nanometers to few microns, and thickness ranging from 1-2 $\mathrm{nm}$ (single layer flakes are reported to be around $1 \mathrm{~nm}$ thick ${ }^{45}$ ) to $20-30 \mathrm{~nm}$, as to indicate the presence of mono- and multi-layers. Larger (non-exfoliated) particles with thickness of hundreds of $\mathrm{nm}$ are also found, yet, they were not considered in the statistical analysis of AFM images. Figure S4 (ESI) shows the average lateral size and the average thickness of verm-US flakes as a function of time and $\mathrm{pH}$. A representative AFM image of a vermiculite sample obtained after $3 \mathrm{~h}$ of exfoliation at $\mathrm{pH} 3.5$ is reported in Figure $4 \mathrm{a}$, together with the distributions of thickness and lateral size of the exfoliated flakes, as obtained by the analysis of AFM images (Figure $4 \mathrm{~b}$ and $\mathrm{c}$ ). In general, both lateral size and thickness decrease as a function of exfoliation time indicating a progressive fragmentation and delamination of vermiculite particles subjected to cavitation forces induced by the ultrasounds. Noteworthy, the initial $\mathrm{pH}$ of the dispersion was found to play a key role in the exfoliation process, with $\mathrm{pH} 3.5$ being the value at which particles with smallest thickness are obtained after $2 \mathrm{~h}$ of exfoliation (ESI, Figure S3). By considering the average thickness-to-lateral size ratio as a parameter to assess the quality of the exfoliated material, the sample exfoliated in $\mathrm{HCl}$ solution at $\mathrm{pH}=3.5$ for $3 \mathrm{~h}$ gives the best results, i.e., the largest flakes with the smallest number of layers were observed. Our results show, that the materials produced in the solutions with $\mathrm{pH}>3.5$ (at constant time) were thicker than those produced at $\mathrm{pH}<3.5$. On the other hand, the size of the exfoliated nanosheets of the materials in the samples prepared at $\mathrm{pH}<3.5$ is much smaller than of that prepared at $\mathrm{pH}>$ 3.5. Under these conditions the lateral size of exfoliated flakes has a broad distribution, with most of the particles being in the 200-600 $\mathrm{nm}$ range, and the thickness distribution centered around $4 \mathrm{~nm}$, indicating the predominance of 3-4 layer-thick vermiculite (Figure $4 \mathrm{~b}$ and $4 \mathrm{c}$ ). Around $10 \%$ of the analyzed flakes display a thickness which can be associated to the presence of vermiculite mono-layers (i.e., $<2 \mathrm{~nm}$ ), while multi-layered aggregates (thickness $>10 \mathrm{~nm}$ ) result to be around $17 \%$ of the analyzed flakes. Reduction in thickness and flake size upon application of ultrasounds under various experimental conditions was previously reported in the literature, with average thickness around $100 \mathrm{~nm}$ or more ${ }^{45}$ and flake size in the order of 1-10 $\mu \mathrm{m} .{ }^{33,45} \mathrm{On}$ one hand, treatment of vermiculite a)

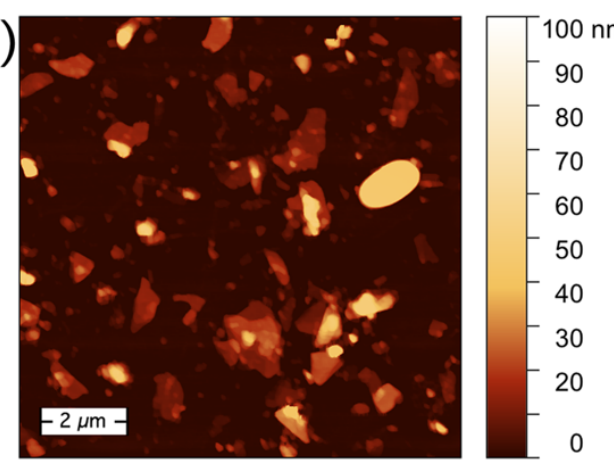

d)

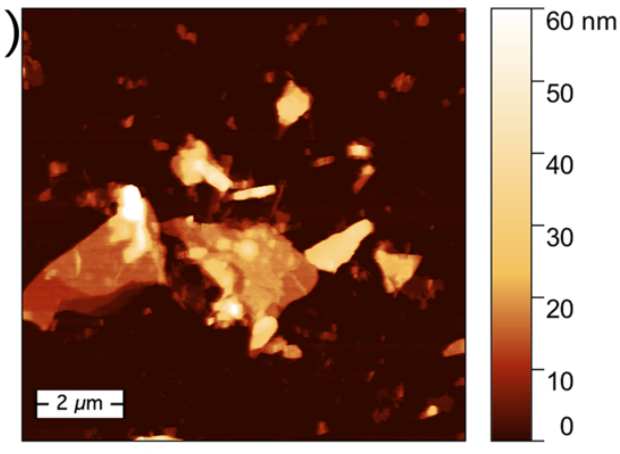

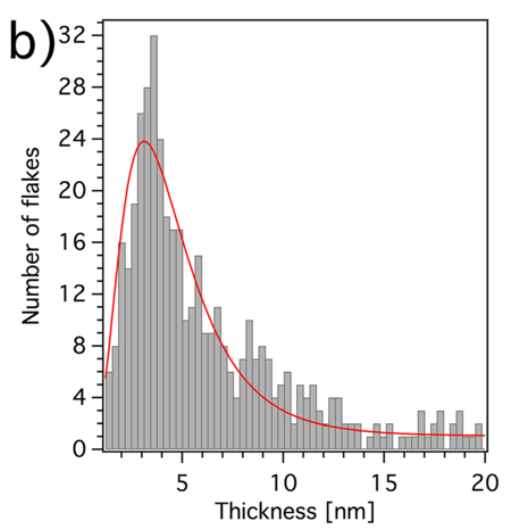

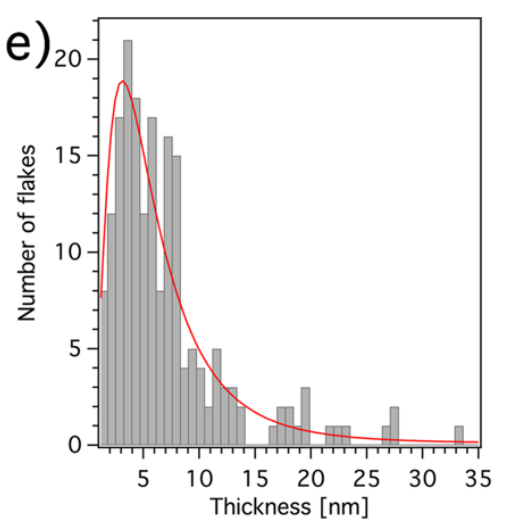

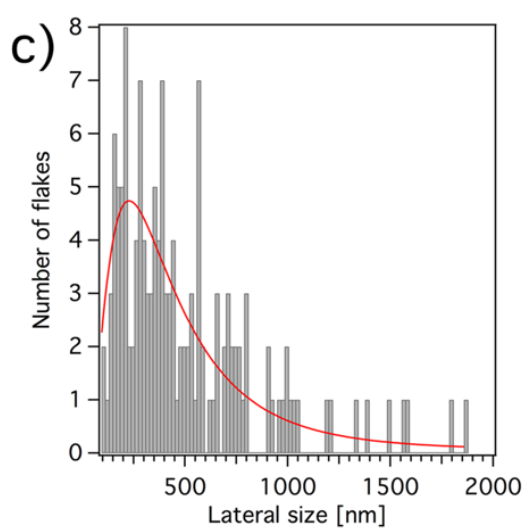

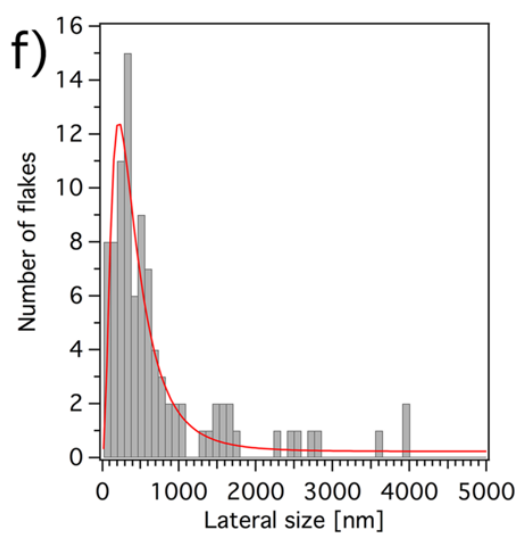

Figure 4. a) Representative AFM image of ultrasound-assisted exfoliated vermiculite at $\mathrm{pH}=3.5,3 \mathrm{~h}$ (scale bar $2 \mu \mathrm{m}$ ); b) thickness (443 flakes analyzed) and c) lateral size (140 flakes analyzed) distribution of ultrasound-assisted exfoliated vermiculite at $\mathrm{pH}=3.5,3 \mathrm{~h}$ obtained from AFM; d) representative AFM image of shear-mixing exfoliated vermiculite (pH 3.5, $20 \mathrm{~min}$ at $3000 \mathrm{rpm}$, scale bar $2 \mu \mathrm{m}$ ) and corresponding e) thickness (195 flakes analyzed) and f) lateral size (96 flakes analyzed) distributions. 
with $0.37 \mathrm{M}(\mathrm{pH}=0.43)$ hydrochloric acid leads in replacing the interlayer $\mathrm{Mg}^{2+}$ with hydrogen ions.64 On the other hand, increasing the acidic strength $(0.75-1 \mathrm{M}, \mathrm{pH}=0.12$ and 0 , respectively) results in, first, dissolving ions from the octahedral sheets and then tetrahedral aluminum ions.64, 65 Further increase of concentration of $\mathrm{HCl}(>2 \mathrm{M})$ leads to total transformation of vermiculite structure to amorphous silica. ${ }^{41}$, ${ }^{64}$ Combination of both, ultrasounds and acid solution, gives the opportunity to use low quantity of acid, which only influences the interlayer ions and supports ultrasonication.

We have then extended our studies to shear-mixing exfoliation (verm-SM). Towards this end, the best-performing experimental conditions/parameters found in the ultrasoundassisted exfoliation, i.e. the initial $\mathrm{pH}=3.5$ as well as the amount of vermiculite powder used in experiment, were employed. As in the case of verm-US, the quality of exfoliated material was analyzed by SEM for different experimental parameters. It revealed that exfoliation at $3000 \mathrm{rpm}$ for about $20 \mathrm{~min}$ was the best compromise in terms of quality of the obtained product and production rate. A direct comparison of the flake size distribution of verm-US and verm-SM (exfoliated at the same $\mathrm{pH}$ ) dispersions obtained by laser diffraction is shown in Figure S7 (ESI). While exfoliation by shear-mixing results in homogenous flake lateral size distribution with a peak centered around $50 \mu \mathrm{m}$ (some larger agglomerates are also present), ultrasound-assisted exfoliation produces nanosheets with a broader flake size distribution, but with a larger fraction of fine particles (see ESI for details). In other words, the ultrasoundassisted exfoliation results to be a more vigorous process with smaller particles being formed, while shear mixing is less effective but able to produce a more homogenous dispersion with larger particle size. The analysis of AFM images (see Figure $4 \mathrm{~d}-\mathrm{f}$ and Figure S8, ESI) taken on solvent-casted dispersions provides direct insights into the flake size obtained after the exfoliation process, as it offers a direct morphological map of the flakes in three dimensions. Conversely, laser diffraction based-techniques provide an indirect characterization of the system, requiring the adoption of a model to treat the data and a certain level of approximation (i.e., the estimated size is given by a volume equivalent spherical diameter). The combination of the two complementary techniques thus provide a complete, statistically-relevant picture of the exfoliated samples, in the dispersed phase and in the solid state. Compared to verm-US, the shear-mixing exfoliated samples display an equivalent number of mono-layer flakes ( $10 \%$ of the analyzed particles) and a thickness distribution peaked around the same value, indicating a majority of 3 layer-thick nanosheets (Figure 4e). However, the thickness distribution is broader than in the case of ultrasound-assisted exfoliation - in particular, the relative number of few layers-thick vermiculite ( $3-4 \mathrm{~nm}$ ) increases from $16 \%$ to $20 \%$ and the number of multilayered flakes (>10 nm) increases from $17 \%$ to $>20 \%$. Moreover, the analyzed flakes display a narrow distribution of lateral size with a peak around $300 \mathrm{~nm}$ (Figure 4f). However, compared to the case of verm-US flakes larger than $2 \mu \mathrm{m}$ are present, indicating that the shearmixing process under these conditions has a less detrimental effect on the reduction of particle size.

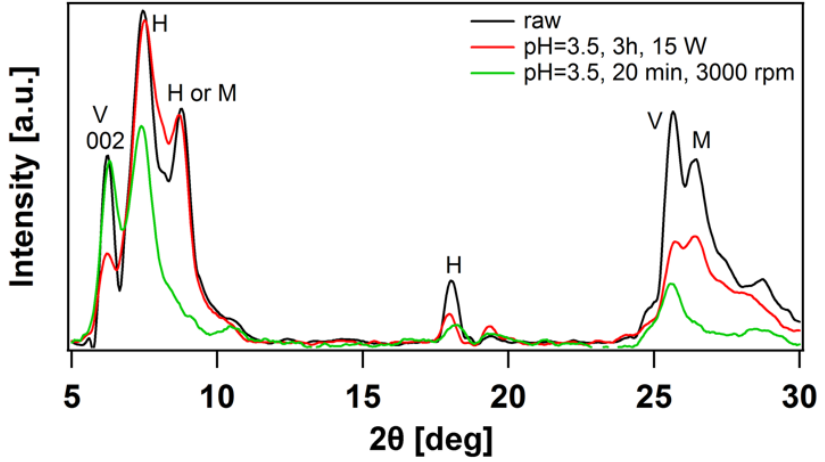

Figure 5. XRD spectra of raw vermiculite (black), verm-US (red) and verm-SM (green) exfoliated at $\mathrm{pH}=3.5$. Letters in the figure indicate vermiculite $(\mathrm{V})$, mica $(\mathrm{M})$ or hydrobiotite $(\mathrm{H})$ crystalline phases.

The X-ray patterns of the raw starting material and of vermiculite exfoliated by ultrasonication and shear mixing (at $\mathrm{pH}=3.5$ ) are displayed in Figure 5. The starting raw vermiculite sample clearly shows a polycrystalline nature. The three main reflections in the low $2 \theta$ range are located at $6.16^{\circ}(\mathrm{d}=1.43 \mathrm{~nm})$, $7.35^{\circ}(\mathrm{d}=1.2 \mathrm{~nm})$ and $8.76^{\circ}(\mathrm{d}=1 \mathrm{~nm})$. A basal spacing of about $1.45-1.55 \mathrm{~nm}$ is characteristic for vermiculite with two water layers in the interlayer space and the presence of magnesium ions between them. ${ }^{66}$ The reflection at $7.35^{\circ}$ could be attributed to the occurrence of partially dehydrated interlayer magnesium ions (one water layer)25, 66 or to hydrobiotite, while the reflection at $8.76^{\circ}$ can be ascribed to the presence of hydrobiotite and mica phases in the structure. At higher $2 \theta$ values, the reflections at $18^{\circ}(\mathrm{d}=0.49 \mathrm{~nm}), 25.56^{\circ}(\mathrm{d}=0.35 \mathrm{~nm})$ and $26.31^{\circ}(\mathrm{d}=0.34 \mathrm{~nm})$ can be attributed to the presence of the hydrobiotite, ${ }^{35}$ pure vermiculite and mica66 phases, respectively. In the diffractogram of verm-US (red curve in Figure 5), the basal spacing is almost intact and the intensity of this reflection is significantly lower. This effect could be explained by partial exchange of interlayer $\mathrm{Mg}^{2+}$ cations for hydrogen ions coming from the acid solution ${ }^{40}$ and by a reduction in flake size caused by ultrasounds. ${ }^{33}$ The next two reflections in the diffraction pattern are almost identical to the raw material, suggesting that ultrasounds only influence the vermiculite layer. All the other peaks display lower intensities but the same position with respect to the starting vermiculite, suggesting that no drastic change occurred in the crystalline structure during the sonication treatment. In the case of vermSM (green curve in Figure 5), the intensity of reflection at about $6.16^{\circ}$ is slightly lower comparing to the raw sample, while the intensity of the next peak drops significantly. The reflections at about $8.76^{\circ}$ is not observed anymore, suggesting that during the exfoliation process hydrobiotite and mica layers are exfoliated keeping the vermiculite layer almost intact. Similar to the case of ultrasound-assisted exfoliation, no significant variations in the diffractogram are observed at higher $2 \theta$ values indicating that the crystalline structure of the layers is not dramatically affected by the exfoliation process, apart from the reflection at $26.31^{\circ}(d=0.34 \mathrm{~nm})$ that is attributed to mica.

The $\mathrm{N}_{2}$ adsorption isotherms of raw and exfoliated vermiculite are shown in Figure S9 (ESI). Specific surface area, as obtained with the BET method, amounts to $6 \mathrm{~m}^{2} / \mathrm{g}$ for the raw mineral, 
$22 \mathrm{~m}^{2} / \mathrm{g}$ and $108 \mathrm{~m}^{2} / \mathrm{g}$ for verm-SM and verm-US ( $\mathrm{pH} 3.5$ ), respectively. The increase of specific surface area (4-fold and 18-fold increment) is a direct consequence of the occurred exfoliation process, while the difference observed with the two methods can be explained by considering the smaller particle size obtained with ultrasounds, as observed by means of AFM and granulometry. Exfoliated vermiculite samples also show a significant increase in the total pore volume (Figure S8, ESI) and a shift of the pore size distribution peak (which can be ascribed mainly to intra-particle voids) towards larger values, suggesting a direct role of the exfoliation process on the meso-scale organization of the clay structure. The absence of micro- and nano-porosity can be taken as a further evidence that the fine structure of the material is retained, i.e. no structural defects are introduced in the clay sheets upon exfoliation.

In order to explore the thermal conductivity of our exfoliated vermiculite, in particular in comparison to the raw bulky vermiculite, we exploited a very simple approach via the use of the transient plane source method (Figure 6). Such measurement enabled to investigate how thermal properties of the material are affected by the exfoliation process. The raw material shows a thermal conductivity of $0.129 \mathrm{Wm}^{-1} \mathrm{~K}^{-1}$, while in the case of the exfoliated samples such value is reduced by about $25 \%\left(\lambda=0.096 \mathrm{Wm}^{-1} \mathrm{~K}^{-1}\right)$, falling in the ultralow thermal conductivity regime $\left(\lambda<0.1 \mathrm{Wm}^{-1} \mathrm{~K}^{-1}\right)$. This variation could be attributed to either a change in the surface chemistry of vermiculite sheets upon partial replacement of exchangeable cations with protons during exfoliation in acid environment, or, more likely, to the variation in the number and stacking order of clay interfaces as suggested by the increase in specific surface area and pore volume of the exfoliated material. Although the measurement methods are different, the results obtained here are in good agreement with those attained on organicallymodified montmorillonite $\left(0.07<\lambda<0.11 \mathrm{Wm}^{-1} \mathrm{~K}^{-1}\right) .{ }^{17}$ a)

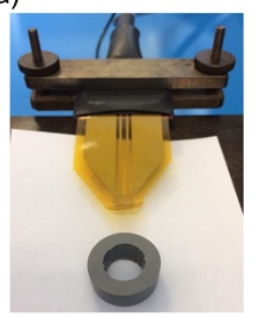

b)

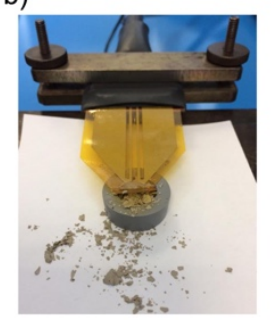

c)

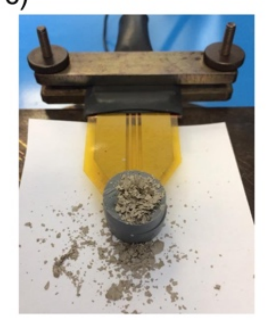

Figure 6. Experimental set-up for the measurement of thermal conductivity with HotDisk TPS 3500: a) sensor and empty sample holder; b) lower part of the sample holder filled with vermiculite powder; c) lower and upper part of the sample holder filled with vermiculite powder.

Table 1. Thermal conductivity $(\lambda)$ of bulk and exfoliated vermiculite

\begin{tabular}{|c|c|c|}
\hline & $\boldsymbol{\lambda}(\mathbf{W m - 1 K}-\mathbf{1})$ & $\boldsymbol{\Delta} \boldsymbol{\lambda} \boldsymbol{\lambda}(\%)$ \\
\hline Raw vermiculite $^{a}$ & 0.129 & - \\
\hline Verm-SM $^{a}$ & 0.096 & -25.6 \\
\hline
\end{tabular}

a $\mathrm{T}=23^{\circ} \mathrm{C}$, b $\mathrm{T}=25^{\circ} \mathrm{C}$
Furthermore, these encouraging results on exfoliated vermiculite suggest the possibility to reach even lower thermal conductivity values by intercalating organic molecules within clay layers and/or by designing more complex self-assembled nanostructures based on exfoliated 2D clay nanosheets. The present thermal characterization results integrate already existing data on vermiculite (traditionally measured by thermogravimetry) and possibly foster the use of the exfoliated clay not only as a barrier to extreme heat conditions (flame resistance) but also as an effective thermally insulating material for everyday applications, e.g. passive house insulation.

\section{Experimental}

\section{Materials}

Hydrochloric acid $(\mathrm{HCl}, \mathrm{ACS}$ reagent, $\geq 37 \%)$, ammonium acetate (for molecular biology, $\geq 98 \%$ ), acetic acid (ReagentPlus ${ }^{\circledR}, \geq 99 \%$ ), ethanol (grade for liquid chromatography, LiChrosolv ${ }^{\circledR}$ ) and vermiculite (batch Z765422, particle size $2-3 \mathrm{~mm}$ ) were purchased from Sigma-Aldrich and used without purification. $\mathrm{Si} / \mathrm{SiO}_{2}$ (oxide thickness $230 \mathrm{~nm}$ ) substrates for AFM and SEM analysis were purchased from Fraunhofer Institute for Photonic Microsystems IPMS. $\mathrm{HCl}$ solution daily consumer goods $\mathrm{s}$ at $\mathrm{pH}$ $=3,3.5,4,4.5$ and 5 were prepared by dilution of concentrated $\mathrm{HCl}$ with distilled water.

\section{Ultrasound-assisted exfoliation of vermiculite (verm-US)}

$1 \mathrm{~g}$ of vermiculite, previously grounded in a mortar, was added to $100 \mathrm{~mL}$ of $\mathrm{HCl}$ solution and then placed in the ultrasonic bath (Bandelin Sonorex, $30 \mathrm{kHz}$ ) for 1 minute. After this time, further exfoliation was carried out using a homogenizer (Bandelin Sonopuls 3100, 20kHz, $15 \mathrm{~W}$, with titanium probe $3 \mathrm{~mm} \times 175$ $\mathrm{mm}, 1-4 \mathrm{~h}$ ). After the experiment, the $\mathrm{pH}$ of dispersion was measured with a Mettler Toledo SevenCompact ${ }^{\mathrm{TM}}$ S220 equipped with InLab ${ }^{\circledR}$ Expert Pro-ISM electrode. If needed, the solid material was collected by filtration through 0.2-0.45 $\mu \mathrm{m}$ PTFE Omnipore ${ }^{\mathrm{TM}}$ membranes (Merck) for further characterization.

\section{Exfoliation of vermiculite using shear-forces (verm-SM)}

$5 \mathrm{~g}$ of vermiculite, previously grounded in a mortar, were added to $500 \mathrm{~mL}$ of $\mathrm{HCl}$ solution at $\mathrm{pH}=3.5$. The exfoliation process was conducted using a shear mixer (Silverson L5M-A, $1000-$ $3000 \mathrm{rpm}, 20 \mathrm{~min}$ ) stocked in a square-hole rotor tip ( $D=32 \mathrm{~mm}$, 96 square holes, $2 \mathrm{~mm} \times 2 \mathrm{~mm}$ each). After the experiment, the $\mathrm{pH}$ of solution was measured. If needed, the solid material was collected by filtration through 0.20-0.45 $\mu \mathrm{m}$ PTFE Omnipore ${ }^{\mathrm{TM}}$ membranes (Merck) for further characterization.

\section{Characterization techniques}

$\mathrm{Si} / \mathrm{SiO}_{2}$ substrates were cleaned with acetone and isopropyl alcohol (sonicated for $30 \mathrm{~min}$ in ultrasonic bath) to remove the protective photoresist layer, and then dried under nitrogen flow. The substrates were then treated with UV-O ${ }_{3}$ (PSD Pro Series, Novascan) for $5 \mathrm{~min}$ followed by $25 \mathrm{~min}$ of exhaust. The 
samples for AFM and SEM characterization were prepared by spray coating/drop casting vermiculite dispersions on top of $\mathrm{SiO}_{2} / \mathrm{Si}$ substrates. The samples were then heated on a hot plate $\left(100^{\circ} \mathrm{C}\right)$ to remove all the remaining water. Morphological characterization was performed by scanning electron microscope (SEM, focused ion beam FEI Helios NanoLab 66) on metalized $(\mathrm{Au})$ samples. The analysis of raw vermiculite was conducted directly on the grounded powder deposited onto a conductive substrate. Atomic force microscopy (AFM) imaging was carried out using a Veeco Dimension 3100 operating on a Nanoscope IV control unit, under ambient conditions. Topographic and phase imaging was performed in tapping mode using antimony $n$-doped silicon tips (resonant frequency= $320 \mathrm{kHz}, \mathrm{k}=42 \mathrm{~N} / \mathrm{m}$; TESPA-V2, Bruker). The thickness and lateral size of the exfoliated vermiculite samples were determined by analysis of AFM images with Gwyddion software (version 2.50). $\mathrm{N}_{2}$ adsorption/desorption isotherms were measured with a Quantachrome Autosorb iQ on degassed samples $\left(100^{\circ} \mathrm{C}\right.$ under vacuum for $12 \mathrm{~h}$ ). All measurements have been performed at least twice on duplicate samples. Specific surface area and pore size distribution were determined using the BET and BJH (on desorption data) method, respectively.

The measurement of vermiculite flakes size in water dispersions were performed by means of diffraction analysis with a Mastersizer 3000 laser analyzer, equipped with a HYDRO-SM wet dispersion unit (Malvern Instruments). Each distribution curve (volume density $\%$ vs size) represents the average of 10 measurements of $5 \mathrm{~s}$ each.

X-ray diffraction diagrams (XRD) were recorded on powder samples with a Bruker AXS D8 Advance, equipped with Johansson monochromator $\left(\lambda \mathrm{Cu} \mathrm{K} \alpha_{1}=.5406 \AA\right)$ and silicon strip detector LynxEye. XRD measurements were performed at a voltage of $35 \mathrm{kV}$ and an intensity of $50 \mathrm{~mA}$.

Thermal conductivity was measured by means of a TPS 3500 (Hot Disk, Göteborg, Sweden) equipped with a standard module, using a Kapton sensor (radius $3.189 \mathrm{~mm}$ ) at room temperature. Measurements were conducted twice on duplicate samples.

\section{Conclusions}

In this study, monolayer- and few layer-thick vermiculite nanosheets were successfully produced via liquid-phase exfoliation by using both ultrasounds and shear-mixing under mild conditions, starting from a low-cost multiphasic material. Based on microscopic characteristics, the best results were obtained in aqueous hydrochloric acid solutions at $\mathrm{pH}=3.5$ during $3 \mathrm{~h}$ in case of ultrasounds-assisted exfoliation, and during $20 \mathrm{~min}, 3000 \mathrm{rpm}$ in case of exfoliation using shear forces. Despite the quality of the material produced with the two methods is similar, the ultrasound-assisted exfoliation yelds thinner flakes. The relative percentage of mono- and bi-layer thick vermiculite sheets obtained with the shear-mixing process amounted to $18 \%$, while in the case of ultrasound-assisted exfoliation such value reaches $27 \%$ (i.e., almost one third of the sample is composed of flakes thinner than $3 \mathrm{~nm}$ ). Furthermore, the material obtained by ultrasound-assisted exfoliation display a larger specific surface area which amounts to $108 \mathrm{~m}^{2} / \mathrm{g}$. As a proof of concept, thermal conductivity measurements were performed on exfoliated vermiculite nanosheets. Compared to the raw bulk mineral, thermal conductivity decreases of around $25 \%$ and reaches the ultra-low thermal conductivity regime (< $\left.0.1 \mathrm{Wm}^{-1} \mathrm{~K}^{-1}\right)$, providing direct evidences on how the change in the material's structure impacts on its thermal properties. The promising thermal characteristics of the exfoliated vermiculite nanosheets combined with the fact of having them as ready-touse aqueous dispersions, suggest their application as inks to create patterns of thermal insulators. A properly formulated vermiculite-based ink could be sprayed, casted or printed on various surfaces, thus possibly fostering the use of $2 \mathrm{D}$ clays not only as a barrier to extreme heat conditions but also as effective thermally insulating elements in everyday devices.

\section{Conflicts of interest}

There are no conflicts to declare.

\section{Acknowledgements}

This work was supported by the European Commission through the Graphene Flagship Core 2 project (GA-785219). The activity in Strasbourg was supported by the Agence Nationale de la Recherche through the LabEx project CSC (ANR-10-LABX-0026 $\mathrm{CSC}$ ) within the Investissement d'Avenir program (ANR-10-120 IDEX-0002-02), and the International Center for Frontier Research in Chemistry (icFRC). The activity in Poznań was supported by the Polish National Science Center (Grant No. 2015/18/E/ST5/00188) and by grant no. POWR.03.02.00-001023/17 co-financed by the European Union through the European Social Fund under the Operational Program Knowledge Education Development. Dr. Alexandre Renault (Thermoconcept, Merignac, France) is acknowledged for the help provided with the thermal conductivity measurements. Dr. M. El Garah is acknowledged for preliminary SEM and AFM studies.

\section{References}

1. F. Bergaya and G. Lagaly, Handbook of Clay Science, Elsevier Science, 2013.

2. J.-J. Lin, C.-C. Chu, M.-L. Chiang and W.-C. Tsai, J. Phys. Chem. B, 2006, 110, 18115-18120.

3. J. L. Suter, D. Groen and P. V. Coveney, Nano Lett., 2015, 15, 8108-8113.

4. M. Stöter, S. Rosenfeldt and J. Breu, Annu. Rev. Mater. Res., 2015, 45, 129-151.

5. M. F. Brigatti, E. Galán and B. K. G. Theng, Structure and Mineralogy of Clay Minerals, Elsevier Science, 2013.

6. J. K. Mitchell and K. Soga, Fundamentals of soil behavior, John Wiley \& Sons Inc., New Jersey, 2005.

7. J. F. Walker, The X-ray identification and crystal structures of clay minerals, Mineralogical Society of Great Britain, London, 1961.

8. P. Lv, C. Liu and Z. Rao, Renew. Sust. Energ. Rev., 2017, 68, 707726. 
9. R. Kozlowski, B. Mieleniak, M. Helwig and A. Przepiera, Polym. Degrad. Stab., 1999, 64, 523-528.

10. Q. Ren, Y. Zhang, J. Li and J. C. Li, J. Appl. Polym. Sci., 2011, 120, 1225-1233.

11. J. E. Connell, E. Metcalfe and M. J. K. Thomas, Polym. Int., 2000, 49, 1092-1094.

12. J. Y. Cheong, J. Ahn, M. Seo and Y. S. Nam, RSC Adv., 2015, 5, 61768-61774.

13. T. Guin, M. Krecker, A. Milhorn, D. A. Hagen, B. Stevens and J. C. Grunlan, Adv. Mater. Interfaces, 2015, 2.

14. S. Lazar, F. Carosio, A.-L. Davesne, M. Jimenez, S. Bourbigot and J. Grunlan, ACS Appl. Mater. Interfaces, 2018, 10, 31686-31696.

15. C. Chiritescu, D. G. Cahill, N. Nguyen, D. Johnson, A. Bodapati, P. Keblinski and P. Zschack, Science, 2007, 315, 351-353.

16. M. D. Losego, M. E. Grady, N. R. Sottos, D. G. Cahill and P. V. Braun, Nat. Mater., 2012, 11, 502.

17. M. D. Losego, I. P. Blitz, R. A. Vaia, D. G. Cahill and P. V. Braun, Nano Lett., 2013, 13, 2215-2219.

18. B. Wicklein, A. Kocjan, G. Salazar-Alvarez, F. Carosio, G. Camino, M. Antonietti and L. Bergstrom, Nat. Nanotechnol., 2015, 10, 277283.

19. K. S. Novoselov, A. K. Geim, S. V. Morozov, D. Jiang, Y. Zhang, S V. Dubonos, I. V. Grigorieva and A. A. Firsov, Science, 2004, 306, 666669.

20. C. Tan, X. Cao, X.-J. Wu, Q. He, J. Yang, X. Zhang, J. Chen, W. Zhao, S. Han, G.-H. Nam, M. Sindoro and H. Zhang, Chem. Rev., 2017, 117, 6225-6331.

21. A. Ciesielski and P. Samorì, Chem. Soc. Rev., 2014, 43, 381-398.

22. F. A. Rasmussen and K. S. Thygesen, J. Phys. Chem. C, 2015, 119, 13169-13183.

23. S.-L. Li, K. Tsukagoshi, E. Orgiu and P. Samorì, Chem. Soc. Rev., 2016, 45, 118-151.

24. R. Mas-Ballesté, C. Gómez-Navarro, J. Gómez-Herrero and F. Zamora, Nanoscale, 2011, 3, 20-30.

25. Y. El Mouzdahir, A. Elmchaouri, R. Mahboub, A. Gil and S. A. Korili, Powder Technol., 2009, 189, 2-5.

26. C. Anichini, W. Czepa, D. Pakulski, A. Aliprandi, A. Ciesielski and P. Samorì, Chem. Soc. Rev., 2018, 47, 4860-4908.

27. D. G. Papageorgiou, I. A. Kinloch and R. J. Young, Prog. Mater. Sci., 2017, 90, 75-127.

28. X. Dong and F. Cheng, J. Mater. Chem. A, 2015, 3, 23642-23652. 29. A. K. Singh, K. Mathew, H. L. Zhuang and R. G. Hennig, J. Phys. Chem. Lett., 2015, 6, 1087-1098.

30. Q. H. Wang, K. Kalantar-Zadeh, A. Kis, J. N. Coleman and M. S. Strano, Nat. Nanotechnol., 2012, 7, 699-712.

31. Z. Xie, C. Xing, W. Huang, T. Fan, Z. Li, J. Zhao, Y. Xiang, Z. Guo, J. Li, Z. Yang, B. Dong, J. Qu, D. Fan and H. Zhang, Adv. Funct. Mater., 2018, 28, 1705833 .

32. O. Udoudo, O. Folorunso, C. Dodds, S. Kingman and A. Ure, Miner. Eng., 2015, 82, 84-91.

33. F. Ali, L. Reinert, J. M. Lévêque, L. Duclaux, F. Muller, S. Saeed and S. S. Shah, Ultrason. Sonochem., 2014, 21, 1002-1009.

34. C. Marcos and I. Rodríguez, Appl. Clay Sci., 2010, 48, 492-498.

35. S. Hillier, E. M. M. Marwa and C. M. Rice, Clay Miner., 2013, 48, 563-582.

36. C. Marcos and I. Rodríguez, Appl. Clay Sci., 2014, 87, 219-227.

37. X. X. Huo, L. M. Wu, L. B. Liao, Z. G. Xia and L. J. Wang, Powder Technol., 2012, 224, 241-246.

38. W. Stawiński, O. Freitas, L. Chmielarz, A. Węgrzyn, K. Komędera, A. Błachowski and S. Figueiredo, Chemosphere, 2016, 153, 115-129. 39. M. Zhao, Z. Tang and P. Liu, J. Hazard. Mater., 2008, 158, 43-51.
40. C. Maqueda, J. L. Perez-Rodriguez, J. Šubrt and N. Murafa, Appl. Clay Sci., 2009, 44, 178-184.

41. A. Steudel, L. F. Batenburg, H. R. Fischer, P. G. Weidler and K. Emmerich, Appl. Clay Sci., 2009, 44, 105-115.

42. S. M. Lee and D. Tiwari, Appl. Clay Sci., 2012, 59-60, 84-102.

43. X.-b. Yu, C.-h. Wei, L. Ke, H.-z. Wu, X.-s. Chai and Y. Hu, J. Colloid. Interface Sci., 2012, 369, 344-351.

44. J. L. Pérez-Rodríguez, F. Carrera, J. Poyato and L. A. PérezMaqueda, Nanotechnology, 2002, 13, 382-387.

45. A. N. Nguyen, L. Reinert, J. M. Leveque, A. Beziat, P. Dehaudt, J. F. Juliaa and L. Duclaux, Appl. Clay Sci., 2013, 72, 9-17.

46. C. Marcos and I. Rodríguez, Appl. Clay Sci., 2011, 51, 33-37.

47. A. Wiewióra, J. L. Pérez-Rodríguez, L. A. Perez-Maqueda and J. Drapała, Appl. Clay Sci., 2003, 24, 51-58.

48. E. Padilla-Ortega, M. Darder, P. Aranda, R. F. Gouveia, R. LeyvaRamos and E. Ruiz-Hitzky, Appl. Clay Sci., 2016, 130, 40-49.

49. G. Chatel, L. Novikova and S. Petit, Appl. Clay Sci., 2016, 119, 193201.

50. M. A. Priolo, K. M. Holder, S. M. Greenlee and J. C. Grunlan, ACS Appl. Mater. Interfaces, 2012, 4, 5529-5533.

51. M. J. Fernández, M. D. Fernández and I. Aranburu, Appl. Clay Sci., 2013, 80-81, 372-381.

52. M. Alexandre and P. Dubois, Mater. Sci. Eng. R Rep., 2000, 28, 163.

53. M. J. Fernández, M. D. Fernández and I. Aranburu, Eur. Polym. J., 2013, 49, 1257-1267.

54. M. Valášková, G. S. Martynková, V. Matějka, K. Barabaszová, E. Plevová and D. Měřínská, Appl. Clay Sci., 2009, 43, 108-112.

55. L. Tran, P. Wu, Y. Zhu, L. Yang and N. Zhu, J. Colloid. Interface Sci., 2015, 445, 348-356.

56. T. A. Saleh, A. Sarı and M. Tuzen, J. Mol. Liq., 2016, 219, 937-945. 57. Y. T. Park, Y. Q. Qian, C. I. Lindsay, C. Nijs, R. E. Camargo, A. Stein and C. W. Macosko, ACS Appl. Mater. Interfaces, 2013, 5, 3054-3062. 58. A. Harvey, J. B. Boland, I. Godwin, A. G. Kelly, B. M. Szydłowska, G. Murtaza, A. Thomas, D. J. Lewis, P. O'Brien and J. N. Coleman, 2D Mater., 2017, 4, 025054.

59. K. R. Paton, E. Varrla, C. Backes, R. J. Smith, U. Khan, A. O'Neill, C. Boland, M. Lotya, O. M. Istrate, P. King, T. Higgins, S. Barwich, P. May, P. Puczkarski, I. Ahmed, M. Moebius, H. Pettersson, E. Long, J. Coelho, S. E. O'Brien, E. K. McGuire, B. M. Sanchez, G. S. Duesberg, N. McEvoy, T. J. Pennycook, C. Downing, A. Crossley, V. Nicolosi and J. N. Coleman, Nat. Mater., 2014, 13, 624-630.

60. K. S. Suslick and G. J. Price, Annu. Rev. Mater. Sci., 1999, 29, 295326.

61. X. Li, Q. Liu, H. Cheng and S. Komarneni, Micropor. Mesopor. Mater., 2017, 241, 66-71.

62. Y. Y. Huang and E. M. Terentjev, Polymers, 2012, 4, 275-295.

63. J. J. Shao, K. Raidongia, A. R. Koltonow and J. X. Huang, Nat. Commun., 2015, 6, 7.

64. H. Suquet, S. Chevalier, C. Marcilly and D. Barthomeuf, Clay Miner., 1991, 26, 49-60.

65. L. Chmielarz, M. Wojciechowska, M. Rutkowska, A. Adamski, A. Węgrzyn, A. Kowalczyk, B. Dudek, P. Boroń, M. Michalik and A. Matusiewicz, Catal. Today, 2012, 191, 25-31.

66. C. Marcos, Y. C. Arango and I. Rodríguez, Appl. Clay Sci., 2009, 42, 368-378. 